after the last delivery. On 15 June 1964 she began to take oral contraceptive tablets Volidan (containing ethinyloestradiol $0.05 \mathrm{mg}$. and megestrolacetate $4 \mathrm{mg}$.). On the sixth day she felt nausea and on the tenth day severe itching. Around the same time the urine became dark and the stools grey. She continued the medication until the 15th day, when menstruation began, and she discontinued the drug intake. A week later she was admitted to hospital; she was markedly icteric and the laboratory examinations showed the following findings.

Blood: Serum bilirubin $8.15 \mathrm{mg} . / 100 \mathrm{ml}$., alkaline phosphatase 3.25 BL-units, serum iron

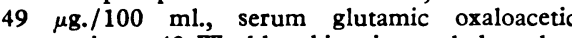
transaminase 40 Wroblewski units, and thrombotest value $100 \%$. Urinalysis showed marked bilirubinuria and urobilinogen.

During the first week of observation the jaundice became more intense and the serum bilirubin and alkaline phosphatase showed marked elevation: serum bilirubin $14.6 \mathrm{mg} . / 100 \mathrm{ml}$, alkaline phosphatase 6.5 BL-units, while the values for serum glutamic oxaloacetic transaminase remained within normal range. Because of the severe obstructive jaundice exploratory laparotomy was decided upon. The liver was of normal size with smooth surface and slightly greenish colour. At operative cholangiography the extrahepatic and main intrahepatic ducts were patent. A liver-biopsy specimen showed severe cholestasis in the central parts of the lobuli which was manifested as "bile emboli" in the ducts and as aggregations in Kupffer cells. No inflammatory changes were encountered, nor manifest cellular degeneration, nor necrosis. These findings corresponded closely with intrahepatic cholestasis.

After the laparotomy the jaundice gradually disappeared and the laboratory values became normal. The duration of the disease was seven weeks.

According to the type of liver damage drugs have been classified into agents producing hepatocellular, hepatocanalicular, or mixed-type injuries. The damage so far attributed to oral contraceptives has previously been of a hepatocellular or mixed type. $^{13}$ In our case, however, the liver damage was of a purely hepatocanalicular one. The hepatitis produced by a number of drugs may be of the cholestatic type in some individuals and of the hepatocellular type in others. ${ }^{5}$ Oral contraceptives may also cause liver lesions of different type in different individuals.

In spite of the work of Dr. Swaab the possibility of hepatic damage during oral contraceptive medication should be kept in mind. Further investigations are necessary in order to establish the relation between these drugs and their effect in the liver. -We are, etc.,

\section{Department of Medicine,} Oulu Finland.

\section{E. Sotaniemi.}

K. E. KREUS.

T. M. SCHEININ.

\section{REPBRENCES}

1 Eisalo, A., Järvinen, P. A., and Luukkainen, T., Brit. med. F., $1964,2,426$.
Fawcett, J. W., and Pedersen, D. L., ibid., 1964, 'Fawcett, J. W., and Pedersen, D. L., ibid., 1964,
2, 755.
Palva, I. P., and Mustala, O. O., ibid., 1964, 2, 688.
Swaab, L. I., ibid., 1964, 2, 755.

- Swaab, L. I., ibid., 1964, 2,755 . cal Pchiff, 1964 , 2nd ed., p. 467 . Pitman Medi-
L Co., London.

\section{New Diuretic-Lasix}

SIR,-Following the report by Dr. W. Stokes and Dr. L. C. A. Nunn (10 October, p. 910) as to the value of Lasix (4-chloro$\mathrm{N}$-(2-furyl-methyl)-5-sulphamoyl anthranilic acid) as a diuretic we thought our recent experience with this drug in a case of gross cardiac failure would be of interest.

This patient had been treated here in June 1962 for severe cardiac failure secondary to mitral valvular disease. $\mathrm{He}$ responded well and returned to work. Later, in spite of digoxin and bendrofluazide, he gradually developed progressive dyspnoea, and peripheral oedema was noted on 14 September 1964. The diuretic was changed to chlorothiazide, but the oedema increased and the patient was given mersalyl $2 \mathrm{ml}$ intramuscularly on 29 September 1964 and 1 October 1964, without response. He was therefore admitted to this hospital on 1 October 1964 under the care of Dr. J. W. Buchanan.

On admission he was semi-conscious and mildly jaundiced. $\mathrm{He}$ had pulmonary congestion, auricular fibrillation at a rate of 120 per minute, and gross right-sided heart failure, with a pulsating liver, engorged neck veins, and gross oedema extending from the ankles to halfway up his back. As the standard diuretics had failed, he was given Lasix $80 \mathrm{mg}$. (two tablets), at 8 p.m. on 1 October 1964. The urine collected in the following 12 hours was $1,100 \mathrm{ml}$, to be followed in successive 24 -hour periods by 4,000 $\mathrm{ml}$., $3,100 \mathrm{ml}$., and $2,000 \mathrm{ml}$., giving a total of $10,200 \mathrm{ml}$. in 84 hours, the intake in this period being $4,790 \mathrm{ml}$.

Throughout this diuresis no electrolytic abnormalities were found, and in particular neither clinical nor biochemical evidence of hypokalaemia developed in spite of no potassium supplements being administered. The blood urea ell from $100 \mathrm{mg}$. per $100 \mathrm{ml}$. on admission to $67 \mathrm{mg}$. per $100 \mathrm{ml}$. on the fifth day, and to normal levels by the seventh day; the carbondioxide-combining power was low on admission and fell to $8 \mathrm{mEq} /$ litre 12 hours after admission, but rapidly returned to normal when sodium bicarbonate $2 \mathrm{~g}$. four-hourly was administered by mouth.

The patient remained semi-conscious, drinking but not talking, until the fifth day, when he became fully rational and claimed to feel fairly well. His jaundice, hepatocellular in type and mild on admission, steadily increased and by the sixteenth day the serum bilirubin was $24.4 \mathrm{mg}$. per $100 \mathrm{ml}$. However, this has since steadily decreased and his serum glutamic pyruvic transaminase, previously 58 international units, is now 20 international units, and it is felt that this jaundice is a result of cardiac cirrhosis with further acute damage, and is not due to Lasix.

We find this case of interest in that Lasix produced a diuresis when other diuretics had failed, that no hypokalaemia developed in spite of a gross diuresis, and that the duration of diuresis (84 hours) far exceeded that previously described for this drug. From these facts we feel that Lasix has passed "the maximum test of a new diuretic"-namely, "the challenge of a patient in anasarca when other proved diuretics have failed." -We are, etc.,

$$
\begin{array}{cl}
\begin{array}{c}
\text { Victoria Hospital, } \\
\text { Kirkcaldy, Fife. }
\end{array} & \text { D. L. H. K. K. SMIth. }
\end{array}
$$

\section{Drugs and Investigations}

SIR,-In a recent article (15 August, p. 435) on general practitioners' letters to hospital much importance was attached to the need for the G.P. to detail the drugs his patient was taking when referring. It is well to remember, however, that self-medication by more and more powerful drugs is becoming increasingly common. A patient of mine (female, aged 19) in a radioactive-iodinetracer study to determine the nature of a goitrous swelling showed a four-hour uptake of ${ }^{132} \mathrm{I}$ of only $8 \%$ (normal $15 \%-30 \%$ ). On repetition of the test the four-hour uptake was still only $6 \%$. She had no clinical signs of hypothyroidism.

After many attempts to unravel this mystery the patient eventually admitted self-medication with 0.25 -g. tablets of Enterovioform (iodochlorhydroxyquinoline) for diarrhoea. I believe Felsol powders for asthma are another easily procurable source of iodine which can produce myxoedema when taken over long periods.-I am, etc.,

Huddersfield, Yorks.

$$
\text { S. L. Henderson SMith. }
$$

\section{Is Arterial Catheterization Dangerous ?}

SIR,-The letter by Dr. H. Ikram and Dr. P. G. F. Nixon (24 October, p. 1072) provides valuable statistical information to be added to the isolated complications of arterial catheterization previously reported in response to Professor W. W. Mushin's inquiry (1 August, p. 310).

Drs. Ikram and Nixon report two instances of femoral artery thrombosis in a series of 92 patients who had left-heart catheterization from the femoral artery using the Seldinger technique. Their experience is similar to that of this unit. We have recently reported four cases of immediate femoral artery thrombosis in a series of 250 selective left angiocardiograms using retrograde Seldinger catheterization via the femoral artery. We have had two further instances in more recent procedures. There have been no known thromboses complicating several hundreds of catheter lumbar aortograms. The discrepancy is probably due to the larger catheters and more prolonged and extensive catheter manipulation required for thoracic and intracardiac angiography.

A much larger series collected by Lang' from 142 American clinics revealed 47 femoral arterial thromboses in 11,402 Seldinger femoral catheterizations for various radiological procedures.

Should arterial thrombosis cause severe ischaemia, immediate thrombectomy should be practised. Anticoagulants should be given, particularly if early operation is not performed.

These complications $(0.5-2 \%)$ emphasize the need for continued and increasing care in performing left-heart catheterization and angiocardiography, and in the selection of patients. They do not indicate that the procedures should be unduly restricted, for they provide information unobtainable by any other means. This information may well he life-saving: to give the simplest example, by excluding a patent ductus prior to open cardiac surgery. As Drs. Ikram and Nixon emphasize, the technique should be restricted to those patients in whom it can be reasonably expected to provide information valuable to that patient's welfare. Arterial catheterization, particularly using large catheters, for primary research purposes (as questioned by Professor Mushin) is, in my opinion, of very questionable ethics.

This belated entry into the correspondence is stimulated by the comparison (implied in the letter by Drs. Ikram and Nixon) between the complications of femoral artery catheterization ( 2 in 92) and those of an indwelling arterial needle in the brachial artery ( 1 in 388). Such a comparison is only valid if the Cournand needle in the brachial artery 